\title{
The Role of a MDP/VBATDT-Primer Composition on Resin Bonding to Zirconia
}

\author{
Anuj Aggarwal ${ }^{1}$ and Grace M. De Souza ${ }^{2, *}$ (iD \\ 1 Faculty of Dentistry, University of Toronto, 124 Edward Street, Toronto, ON M5G1G6, Canada; \\ dranuj@yahoo.com \\ 2 Department of Clinical Sciences, Faculty of Dentistry, University of Toronto, 124 Edward Street, \\ Toronto, ON M5G1G6, Canada \\ * Correspondence: grace.desouza@dentistry.utoronto.ca; Tel.: +1-416-8648206
}

Received: 26 February 2018; Accepted: 4 April 2018; Published: 7 April 2018

\begin{abstract}
Yttria-tetragonal zirconia polycrystal (Y-TZP) is a difficult substrate to bond to due to the absence of a glass phase and the material's chemical inertness. This study evaluated the effect of two monomers for metal, MDP (10-methacryloyloxydecyl dihydrogen phosphate) and VBATDT (6-(4-vinylbenzyl-n-propyl)amino-1,3,5-trizaine-2,4-dithiol) on bond strength to Y-TZP. Seven combinations with different concentrations of MDP and VBATDT-monomers (0.0, 0.1, 0.5, or $1.0 \mathrm{wt} \%$ ) in acetone solution were developed and applied to the surface of Y-TZP slabs, which were bonded to composite resin substrates using a resin cement under standard loading. Non-primed samples were used as controls. Bonded specimens were cut for microtensile testing and tested after either $48 \mathrm{~h}$ or 180 days in water storage at room temperature. All samples from control group (no primer) and MV5 group ( $0 \%$ MDP /0.5\% VBATDT) debonded spontaneously. Two-way ANOVA showed that the primer had a significant effect $(p<0.001)$ on bond strength to zirconia, whilst storage time did not $(p=0.203)$. Tukey HSD (honest significant difference) test indicated that groups with at least $0.5 \%$ of each monomer resulted in higher initial bond strength values. Although chemical bonding to zirconia is credited to MDP, a correct balance between MDP and VBATDT may imply in better bond strength results. The minimum concentration of each monomer should not be lower than $0.5 \mathrm{wt} \%$.
\end{abstract}

Keywords: high-crystalline content zirconia; active monomers; oxide layer

\section{Introduction}

Three mol \% yttria-tetragonal zirconia polycrystalline (Y-TZP) is a ceramic used in a variety of applications, such as thermal barrier protection in aero and industrial gas turbines, oxygen sensors and fuel cell membranes [1]. Y-TZP is also the strongest ceramic available for application in dentistry and orthopedics, which makes it highly indicated to replace missing posterior teeth $[2,3]$. Furthermore, the combination of zirconia and porcelain veneer coverage results in a highly aesthetic dental restoration [4]. Nonetheless, achieving good adhesion between zirconia-based prosthesis and resin cements is a challenge given the low bond strength values between these two substrates which are a consequence of the crystalline content of Y-TZP [5,6]. Hydrofluoric acid, for example, dissolves the glass phase of silica-based ceramics increasing surface area, but it does not modify the surface morphology of Y-TZP [7]. Airborne particle abrasion is an alternative to increase the inner surface roughness of Y-TZP copings, in an attempt to improve micromechanical interlocking and, consequently, the bond strength to resin cements [8,9]. However, it has been shown that sandblasting the zirconia surface for $5 \mathrm{~s}$ with particles of $\sim 50 \mu \mathrm{m}$ creates surface damage and reduces cyclic fatigue resistance in approximately $30 \%$, by introducing flaws that would propagate under cyclic loading and, 
therefore, compromise the longevity of all-ceramic restorations [10]. A decrease in reliability of $110 \mu \mathrm{m}$ particle-abraded zirconia specimens has also been demonstrated [11]. Nonetheless, according to Scherrer et al. [12], airborne particle abrasion using $30 \mu \mathrm{m}$ alumina particles not only avoids undesired damage to the surface, but also improves the fatigue behavior of some materials [12]. However, sandblasting, itself, does not promote high bond strength to different luting systems $[5,13]$ and the composition of the resin-based luting system is more critical than the size of the particles employed for surface abrasion [14].

The chemical inertness of zirconia also represents a challenge in the luting process, due to its low surface energy and wettability [15]. Additionally, its nonpolar surface has high corrosion resistance and does not chemically interact with potentially adhesive materials [16]. Considering that Y-TZP is essentially zirconium oxide [17], the application of primers developed for metal bonding may improve the bond strength between zirconia and luting systems, without causing further mechanical damage to the structure of the material [18]. 10-Methacryloyloxydecyl dihydrogen phosphate (MDP) is a monomer with high affinity to base metals [19]. The hydroxyl groups of the oxide layer on Y-TZP seem to react with the phosphate ester monomer of the MDP, leading to strong chemical reactions at the interface between the two materials [20]. The better bond strength may be due to either Van der Walls forces or hydrogen bonds [21]. MDP-based materials have been used in association with airborne particle abrasion $[8,9,22]$ or without any mechanical modification of the surface $[19,23,24]$, and results indicate that the bond strength between zirconia and resin cement is higher when MDP-based materials are employed, irrespective of the mechanical treatment [20,25]. However, the six-month stability of the MDP-mediated bonding and non-sandblasted zirconia is questionable [24].

Interestingly, in a previous study developed by our research group, only the application of a commercial primer containing MDP and 6-(4-vinylbenzyl-n-propyl)amino-1,3,5-triazine-2,4-dithione (VBATDT) was capable of promoting high and stable bond strength to Y-TZP intaglio's surface as opposed to a primer containing only MDP [19]. Similar results were obtained when that primer was compared to other commercial primers making use of different monomers [23]. The successful primer is a solution of MDP and VBATDT dispersed in acetone and the ratio between the two monomers is not disclosed by the manufacturer. Considering that this primer was developed for bonding to metal infrastructures [26], it can be hypothesized that the formulation is not optimized for Y-TZP-based substrates, and that variations in the ratio between the two monomers may clarify the importance of each of them on bonding to Y-TZP.

Therefore, this study evaluated the effect of both, MDP and VBATDT, on bonding and stability of the bonding between Y-TZP and resin-based cement. This was assessed by developing experimental solutions with different ratios of both molecules and evaluation of the bond strength at different storage times. The null hypotheses were that bond strength is not affected by the composition of the primer and that storage time has no effect on bond strength.

\section{Materials and Methods}

Materials used in this study are listed in Table 1. Fully-sintered zirconia cylinders ( $97 \%$ zirconium dioxide stabilized with 3\% yttria-lava frame, 3 M ESPE, St. Paul, MN, USA) with $19 \mathrm{~mm}$ diameter and $100 \mathrm{~mm}$ height were cut to obtain 20 slices with $4 \mathrm{~mm}$ thickness. The disc-shaped slices had both faces ground up to 600 grit carbide silicon paper (Buehler Canada, Whitby, ON, Canada) under water cooling pressure. An impression of one of the slices was taken and $6 \mathrm{~mm}$-thick composite resin substrates (Clearfil Majesty Esthetic, Kuraray America Inc., Huston, TX, USA) were incrementally built, with each $1 \mathrm{~mm}$ layer being light-activated for $40 \mathrm{~s}\left(850 \mathrm{~mW} / \mathrm{cm}^{2}\right.$, VIP Jr., Bisco Inc., Schaumburg, IL, USA). Light-output was confirmed throughout the study using a laboratory-graded spectroradiometer (CheckMARC, BlueLight Analytics, Halifax, NS, Canada). The composite resin substrates were aged in deionized water for 30 days to provide hydration and avoid later hygroscopic expansion. After the storage period, both sides of each composite resin sample were finished using the same method described for Y-TZP samples, so that flat surfaces of standard roughness could be produced. 
Y-TZP and composite resin substrates were cut in half with a diamond blade under water cooling, to generate 40 samples of each material. Samples were ultrasonically cleaned in distilled water for $10 \mathrm{~min}$ and stored in distilled water at room temperature.

Table 1. Names, formulation, and additional information about the materials employed.

\begin{tabular}{|c|c|c|}
\hline \multicolumn{3}{|c|}{ Commercial Materials } \\
\hline $\begin{array}{c}\text { Material } \\
\text { Manufacturer }\end{array}$ & Classification & Composition \\
\hline $\begin{array}{c}\text { Lava Frame } \\
3 M \text { ESPE, St. Paul, MN, USA }\end{array}$ & High-crystalline content zirconia & $97 \mathrm{~mol} \%$ zirconium dioxide and $3 \mathrm{~mol} \%$ yttrium dioxide \\
\hline $\begin{array}{l}\text { Clearfil Majesty Esthetic } \\
\text { Kuraray America, Inc., New York, NY, USA }\end{array}$ & $\begin{array}{c}\text { Light-cure nanohybrid resin composite, } \\
\text { shade A2 }\end{array}$ & $\begin{array}{l}\text { BisGMA, hydrophobic aromatic dimethacrylate, } \\
\text { hydrophobic aliphatic methacrylate, silanated barium } \\
\text { glass filler, pre-polymerized organic filler } \\
\text { dl-Camphorquinone }\end{array}$ \\
\hline $\begin{array}{c}\text { Clearfil Esthetic Cement EX } \\
\text { Kuraray America, Inc., New York, NY, USA }\end{array}$ & Self-etch dual-cure resin-based cement & $\begin{array}{l}\text { BisGMA, TEGDMA, hydrophobic aromatic } \\
\text { dimethacrylate, silanated silica filler, silanated barium } \\
\text { glass filler, colloidal silica }\end{array}$ \\
\hline \multicolumn{3}{|c|}{ Experimental primers } \\
\hline MV1 & \multicolumn{2}{|c|}{$0.5 \mathrm{wt} \% \mathrm{MDP}$ and $0.0 \mathrm{wt} \%$ VTATDT in acetone } \\
\hline MV2 & \multicolumn{2}{|c|}{$0.5 \mathrm{wt} \% \mathrm{MDP}$ and $0.1 \mathrm{wt} \%$ VBATDT in acetone } \\
\hline MV3 & \multicolumn{2}{|c|}{$0.5 \mathrm{wt} \% \mathrm{MDP}$ and $0.5 \mathrm{wt} \%$ VBATDT in acetone } \\
\hline MV4 & \multicolumn{2}{|c|}{$0.5 \mathrm{wt} \% \mathrm{MDP}$ and $1.0 \mathrm{wt} \%$ VBATDT in acetone } \\
\hline MV5 & \multicolumn{2}{|c|}{$0.0 \mathrm{wt} \% \mathrm{MDP}$ and $0.5 \mathrm{wt} \%$ VBATDT in acetone } \\
\hline MV6 & \multirow{2}{*}{\multicolumn{2}{|c|}{$\begin{array}{l}0.1 \mathrm{wt} \% \mathrm{MDP} \text { and } 0.5 \mathrm{wt} \% \text { VBATDT in acetone } \\
1.0 \mathrm{wt} \% \mathrm{MDP} \text { and } 0.5 \text { wt } \% \text { VBATDT in acetone }\end{array}$}} \\
\hline MV7 & & \\
\hline
\end{tabular}

BisGMA: bisphenol A diglycidylmethacrylate; TEGDMA: triethylene glycol dimethacrylate; MDP: 10Methacryloyloxydecyl dihydrogen phosphate; VBATDT: 6-(4-vinylbenzyl-n-propyl)amino-1,3,5- triazine-2,4dithione.

Zirconia and composite resin blocks were randomly assigned to one of 8 test groups $(n=5)$, seven experimental and one control group, according to the treatment to be applied. Seven combinations of MDP (10-methacryloyloxydecyl dihydrogen phosphate) and/or VBATDT (6-(4-vinylbenzyl-n-propyl)amaino-1,3,5-trizaine-2,4-dithiol) primers were developed and the final composition may be seen in Table 1 . Monomer ratios were calculated by weight percent ( $\mathrm{wt} \%)$ and acetone was used as a solvent. One group with no primer application was designated as control.

The Y-TZP surface was air-dried and two layers of the primer were applied with a microbrush. After $60 \mathrm{~s}$, solvent was removed with a gentle air blast. Composite resin surfaces were prepared following the directions of the resin cement manufacturer. Dual cure cement (Clearfil Esthetic Cement EX, Kuraray America Inc., New York, NY, USA) was placed on the treated zirconia surface and the composite substrate was placed over the cement and held under a $600 \mathrm{gf}$ load. The excess cement was removed with a spatula and light-activation was performed perpendicular to the adhesive interface at four different locations around the sample $\left(40 \mathrm{~s}\right.$ each at $850 \mathrm{~mW} / \mathrm{cm}^{2}$, VIP Jr., Bisco Inc., Schaumburg, IL, USA). Cemented samples were stored in deionized water at room temperature $\left(\sim 22^{\circ} \mathrm{C}\right)$.

After $24 \mathrm{~h}$ storage, slabs were obtained by cutting the blocks perpendicularly to the adhesive interface with a diamond blade under water cooling. A second cut, perpendicular to the first one, was carried out resulting in beams of approximately $1 \mathrm{~mm}^{2}$ cross-sectional area and $10 \mathrm{~mm}$ length. Specimens were then stored in deionized water at room temperature $\left(\sim 22^{\circ} \mathrm{C}\right)$ and tested after two aging periods: $48 \mathrm{~h}$ and 180 days. For the longer storage groups (180 days), water was replaced on a weekly basis.

Five beams were randomly selected from each sample for the microtensile testing. The remaining beams were kept in deionized water. Each specimen was individually attached to a special jig with cyanoacrylate glue (Krazy Glue, Elmers Products, High Point, NC, USA). Testing was performed in a universal testing machine (Model 5565, Instron Corp., Norwood, MA, USA) at a crosshead speed of $0.5 \mathrm{~mm} / \mathrm{min}$ and the load at failure was recorded. The dimensions of each beam at the bonded interface were measured with a digital caliper to determine the cross-sectional area and nominal bond strength (in $\mathrm{MPa}$ ) was calculated. After 180 days, five beams were randomly selected again from each sample and the bond strength test was repeated following the same protocol. Both portions 
of each tested beam were evaluated under stereomicroscope (60× magnification, Olympus SZ61, Olympus America Inc., Center Valley, PA, USA) and the mode of failure was classified as type 1 (adhesive between ceramic and cement), type 2 (adhesive between composite and cement), or type 3 (mixed failure). One entire sample (both zirconia and composite resin portions) from each group and each mode of failure was selected for electron scanning microscopy (SEM-JEOL JSM-66 10 LV, Tokyo, Japan) after sputter coating with carbon for $10 \mathrm{~s}$.

For statistical purposes, each cemented sample was considered as the experimental unit $(n=5)$ and beams were considered repetitions within the same sample. A two-way ANOVA was conducted to evaluate the effect of treatment and storage time on bond strength. Tukey HSD (honest significant difference) was applied to compare the experimental groups $(p=0.05)$. If present, it was determined beforehand that any pre-test failure would be treated as $0 \mathrm{MPa}$.

For the analysis of the atomic composition of the primers used, flat surfaces of Y-TZP $\left(4 \times 4 \times 1 \mathrm{~mm}^{3}\right)$ were prepared as previously described and treated with two layers of the corresponding primer, which was left undisturbed for one minute, after which it was vigorously air-dried. Non-sputter-coated control and primer-treated samples were analyzed under energy dispersive X-ray spectroscopy (EDS) analysis in an electron scanning microscope (JEOL, Tokyo, Japan) fitted to an EDS detector (silicon drift detector with INCA data acquisition, Oxford Instruments, Abingdon, UK).

\section{Results}

\subsection{Microtensile Bond Strength Test}

All the samples from group MV5 and control group debonded prior to the microtensile test, and their bond strength values were included as $0 \mathrm{MPa}$ (zero MPa) for statistical purposes. No pre-test failures were observed for any of the other groups, and approximately 12-16 beams were obtained from each sample. The two-way ANOVA was performed for the remaining groups. Primer had a significant effect on bond strength results $(p<0.001)$ and there was no effect of storage time $(p=0.203)$. The interaction primer versus time $(p=0.190)$ was not significant.

Descriptive statistics (means and standard deviations) of the bond strength data and results of the Tukey HSD test $(p=0.05)$ are shown in Table 2. The highest mean bond strength was presented by samples treated with MV3 $(13.7 \pm 5.0 \mathrm{MPa})$, which was similar to MV4 $(12.2 \pm 3.8 \mathrm{MPa})$ and MV7 $(11.9 \pm 4.0 \mathrm{MPa})$ treated samples. Groups with the lowest percentage of any of the components (MV1, MV2 and MV6) presented the lowest bond strength results (Table 2).

Table 2. Means (standard deviation-SD) of microtensile bond strength and Tukey HSD results for primer irrespective of aging time.

\begin{tabular}{cc}
\hline Treatment & Mean $^{*}(\mathrm{SD})$ \\
\hline MV3 & $13.7(5.0)^{\mathrm{A}} \mathrm{A}^{\mathrm{AB}}$ \\
MV4 & $12.2(3.8)^{\mathrm{B}}$ \\
MV7 & $11.9(4.0)^{\mathrm{AB}}$ \\
MV1 & $11.0(3.5)^{\mathrm{B}}$ \\
MV2 & $10.3(3.4)^{\mathrm{B}}$ \\
MV6 & $9.3(3.8)^{\mathrm{B}}$ \\
MV5 & $0.0(0.0)^{\mathrm{C}}$ \\
\hline Control & $0.0(0.0)^{\mathrm{C}}$
\end{tabular}

* Bond strength values expressed in $\mathrm{MPa}$; ${ }^{* *}$ Similar letters within the same column indicate statistically similar bond strength results at $5 \%$ significance level. 


\subsection{Mode of Failure}

Incidence of mode of failure for all experimental groups at both storage times is shown in Figure 1. Analysis of mode of failure indicated that there was a decrease in type 1 (between ceramic and cement) failure after aging for all groups evaluated. MV3-treated groups presented higher incidence of type 2 failure (between composite and cement) at both storage times. Lower bond strength values were associated with higher incidence of type 1 failure (groups MV1, MV2, and MV6). Pre-test failed samples (control and MV5-treated) showed 100\% incidence of type 1 failure.

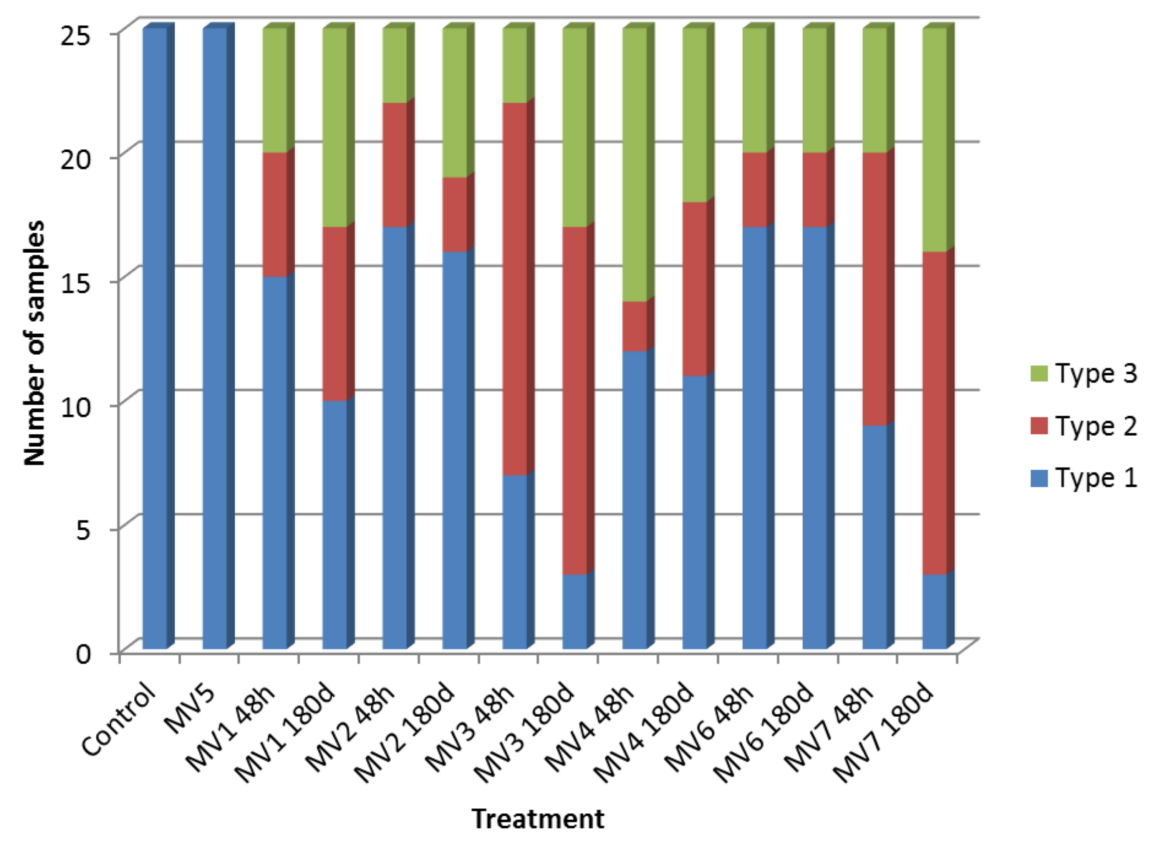

Figure 1. Incidence of mode of failure for each experimental group at different storage times.

\subsection{Energy Dispersive Spectroscopy}

Analysis of the atomic composition of the primers applied on the Y-TZP surface indicated that the molecules were not evenly distributed. Control sample, as expected, only indicated the presence of zirconium, oxygen, and carbon (yttrium was not identified as a possible element to be encountered) (Figure 2A). MV1 resulted in a film with some areas having higher concentration of phosphorous and structures that appeared like "droplets" of higher carbon concentration, which was similar to the MV2-treated surface. Application of MV3 resulted in a homogeneous film spread on the surface, with even distribution of sulfur-rich and phosphorous-rich areas. MV4 resulted in a thin film characterized by higher concentration of zirconium (Figure 2B) and droplets with higher concentration of carbon and sulfur (Figure 2C). This was similar to MV7-treated surface, which showed a thin film (gray area) with a distribution of dark spots rich in carbon, phosphorous, and sulfur (Figure 2D). The MV5-treated surface showed a thin film throughout the surface where high concentration of zirconium was observed, and seldom areas with low peaks of sulfur could also be encountered. For the MV6-treated surface, there was a more subtle incidence of darker spots with slightly higher concentration of sulfur and carbon in a thin film indicated by higher peaks of zirconium. 

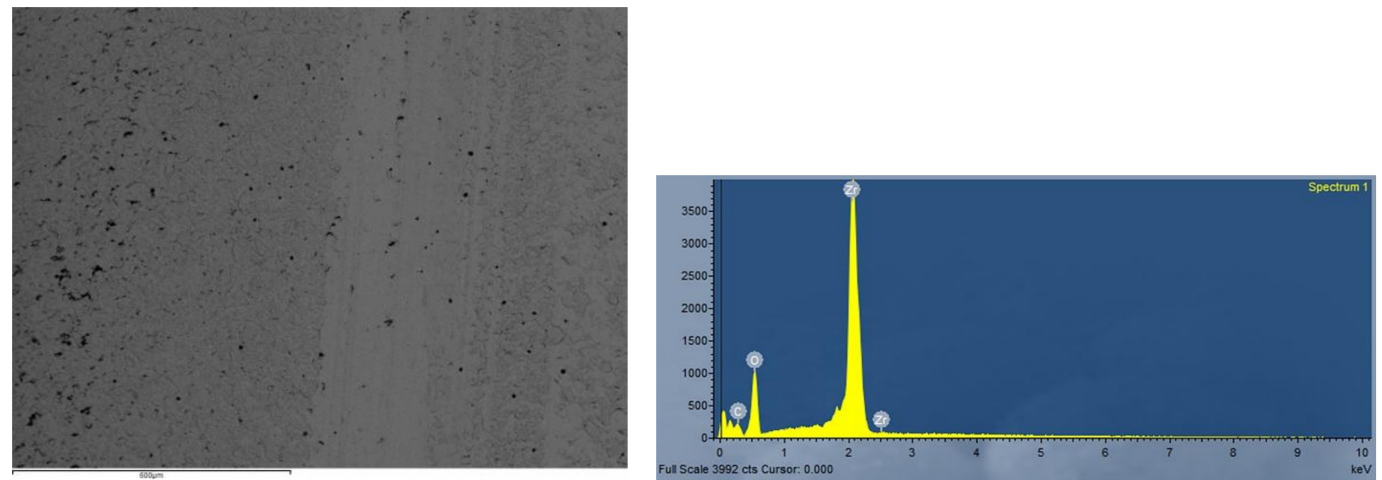

(A)
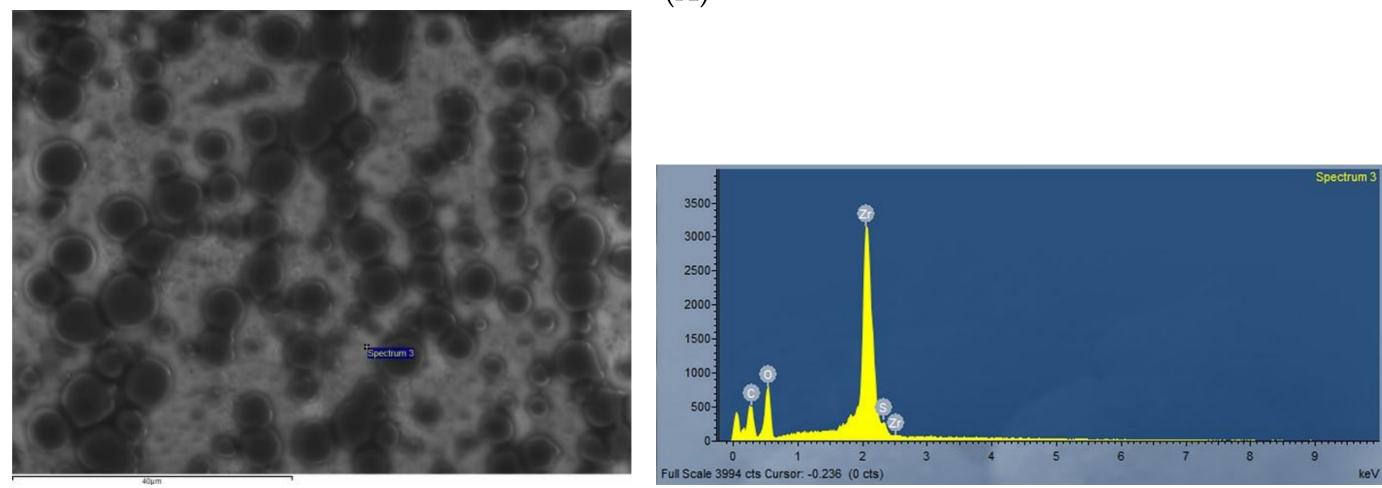

(B)
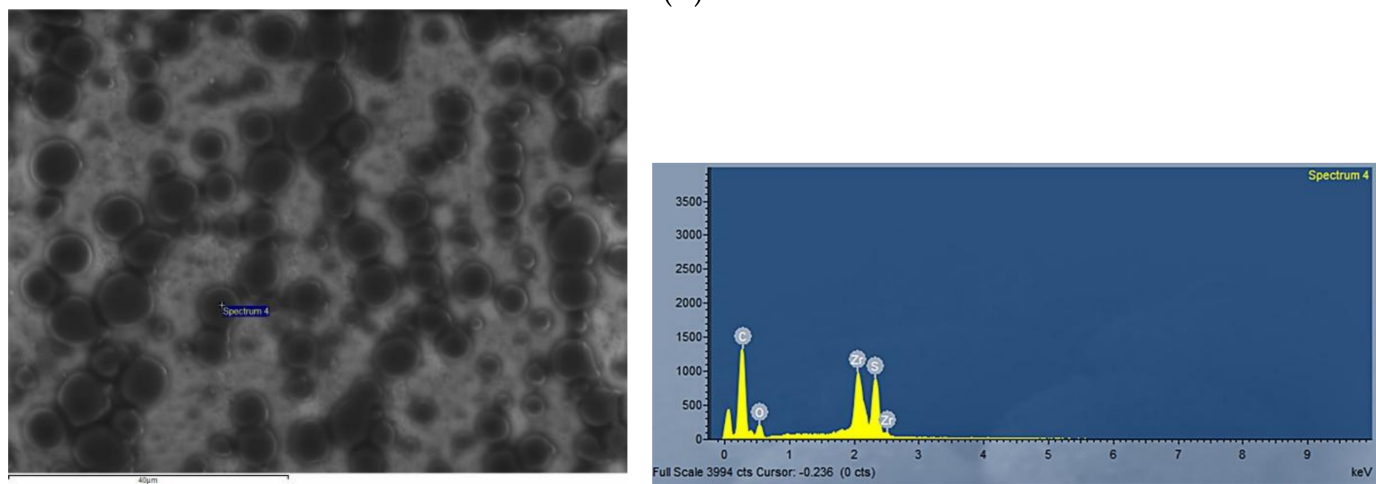

(C)
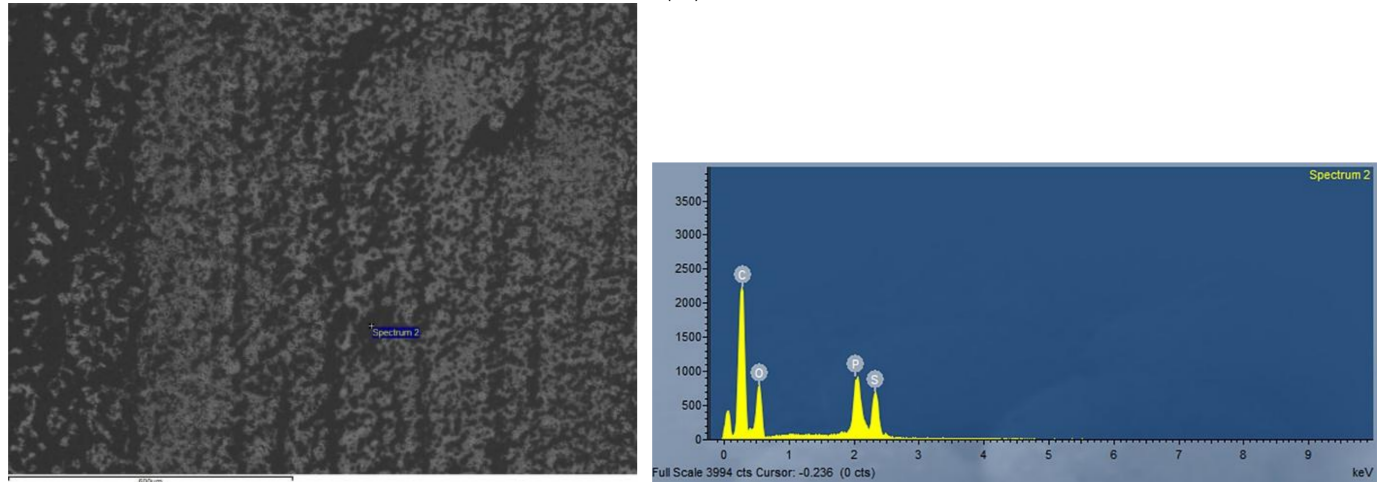

(D)

Figure 2. SEM of primer-treated Y-TZP samples and spectra presented by energy dispersive $\mathrm{X}$-ray spectroscopy. (A) Control sample indicating high peaks of zirconium, oxygen, and carbon; (B) MV4-treated surface, with a thin film coverage evidenced by high peaks of zirconium; Darker spots seen on (C) (spectrum 4) show a higher concentration of sulfur and carbon covering the zirconium surface. (D) MV7-treated surface, where high peaks of carbon, phosphorous, and sulfur are evidenced in the darker areas (spectrum 2), compatible with high concentration of both monomers (carbon and phosphorous from MDP and carbon and sulfur from VBATDT). 


\section{Discussion}

The present study evaluated the effect of different ratios of two monomers-MDP and VBATDT-on bond strength between Y-TZP and resin-based luting system. To avoid any unexpected effect of the cement's chemistry on bond strength, the resin-based cement selected did not contain either MDP or any other functional monomer in its composition. It has already been demonstrated that MDP-containing cements result in higher and more stable bond strength than the one used in the current investigation (Clearfil Esthetic Cement) [27]. Indeed, depending on the chemistry of the resin-based cement, it can outperform the chemical impact of the primer treatment, eliminating possible effects of the primer on bonding to Y-TZP $[23,28]$. Additionally, Y-TZP samples were not air-abraded with alumina particles, which would have had an effect on surface roughness [29], possibly increasing micromechanical interlocking by the penetration of the resin cement into the microretentions created $[14,30]$. Therefore, it is possible to say that the bond strength results reported in the present study are strictly related to the chemical interaction between Y-TZP oxide layer and primer, and between primer and resin cement.

Analysis of the microtensile bond strength results indicated that primer had a significant effect $(p<0.001)$ on bond strength between Y-TZP and resin cement. Therefore, the first null hypothesis was rejected. The treatment with MV3 resulted in superior bond strength results when compared to MV1, MV2, and MV6. The effectiveness of the bonding between MV3 and Y-TZP was also confirmed by the high incidence of type 2 mode of failure, indicating that the weak link on those samples was between resin cement and composite resin substrate. MV3 primer had a similar ratio $(0.5 \mathrm{wt} \%)$ between the two monomers of interest-MDP and VBATDT, and the bond strength results of MV3 at $48 \mathrm{~h}$ were significantly higher than those presented by groups where VBATDT content was absent or lower (MV1 and MV2-0.0 wt \% and $0.1 \mathrm{wt} \%$, respectively), indicating that VBATDT may be a critical molecule for bonding to zirconia substrates, which has not yet been reported in the literature. A previous study published by our research group indeed showed that a MDP only-based primer resulted in significantly lower bond strength than a MDP/VBATDT-based primer [19]. Many other studies have already reported successful outcomes when MDP/VBATDT-primer is used to bond to Y-TZP $[18,19,28,31-33]$. One might argue that the successful combination between MDP and VBATDT has already been demonstrated by the extensive published research evaluating the efficacy of Alloy Primer (commercial brand) on bonding to zirconia [26]. However, the ratio between the two monomers has not been disclosed by the manufacturer (Kuraray America Inc., Huston, TX, USA), making it difficult to assess which one of the monomers plays the most important role on Y-TZP surface adhesion. Indeed, the importance of the synergistic effect of both, MDP and VBATDT, on initial bond strength between Y-YZP and resin cement, had not been considered before.

The similar importance of both monomers on the chemical interaction with Y-TZP is evidenced when MV3 results are compared to MV4 and MV7. The higher concentration of either MDP (MV7) or VBATDT (MV4) was not capable of improving bond strength results (Table 2). MDP has two functional groups, one is a di-valent phosphoryl group which is possibly adsorbed onto the Y-TZP surface, and the other is a methacryloyl group that copolymerizes with resin monomers either in the adhesive or in the resin cement composition [27]. VBATDT is a thione-thiol tautomer developed to improve the bonding between noble metal alloys and methacrylate-based resins. The coupling mechanism occurs by transforming thione in thiol and formation of the bond on the metal surface, and copolymerization of the vinyl groups with the resin cement [34]. Although further studies are necessary to precisely describe the mechanism of action of the VBATDT-molecule on the surface of Yttria-stabilized zirconium dioxide, we hypothesize that the thione-thiol group bonds to the largely available oxide layer of zirconia, somewhat contributing to the bond strength values. FTIR analysis has been able to demonstrate the crystalline VBATDT embedded in the amorphous MDP solution, indicating good miscibility between them [34] and leading to the hypothesis that one helps the other on bonding to metal substrates, increasing bond strength values [31]. Based on our findings, it is possible to speculate that the same is true for the surface of zirconium dioxide $\left(\mathrm{ZrO}_{2}\right)$, that the miscibility 
of both monomers created a thin and uniform layer that resulted in superior bonding due to the homogeneous distribution of stresses through the adhesive interface. The bonding was also chemically stable. The interaction between both monomers is evidenced by the EDS images of the Y-TZP surface treated with different primers. Figure 2B (MV4-spectrum 3) shows high peaks of carbon and zirconium and is related to the MDP amorphous phase. Figure 2C (MV4-spectrum 4) shows higher peaks of carbon and sulfur, which is present in the VBATDT molecule. The zirconium peak observed in this spectrum is much lower, indicating that zirconium has been shadowed by the crystalline structure of VBATDT. The homogeneous distribution of both monomers in the solution is characterized on Figure 2D (MV7), where VBATDT is dispersed throughout the MDP amorphous phase. The analysis of the results also shows that the MV4 and MV7-treated samples presented bond strength values that were similar to MV1, MV2, and MV6-treated samples. This result may reflect the dissimilar ratio between MDP and VBATDT monomers in MV4 and MV7 compositions, whereby higher and balanced concentration of both monomers might have led to improved bond strength. The investigation of the effect of higher and balanced concentrations of MDP and VBATDT up to a saturation level is of great interest to clarify whether or not the chemical bonding between resin cement and Y-TZP can be maximized.

The lowest bond strength results were obtained when the concentration of one of the monomers was reduced, either MDP (MV6) or VBATDT (MV2). This further indicates that the association of both monomers seem to be the key to succeed when bonding to Y-TZP. When MDP was absent in the formulation (MV5), all of the samples debonded prematurely. Sample preparation for microtensile testing is very critical, especially when a very hard and tough substrate, like fully-sintered Y-TZP, needs to be cut through the adhesive interface. The vibration of the diamond blade may cause a high incidence of pre-test failures. Although this was not experienced with any other group, samples treated with MV5 could not withstand the challenges of sample preparation. A bond strength of at least $5 \mathrm{MPa}$ is necessary for the samples to survive microtensile sample preparation [35]. However, bond strength values as low as 4.3 MPa were reported in a previous study using the same technique [24], indicating that the bonding promoted by MV5 primer was probably inferior to $4.3 \mathrm{MPa}$. The primer application per se was expected to improve bond strength between Y-TZP and resin cement due to the improved wettability [30,36]. Kim et al. (2011) observed that the contact angle between zirconia and resin cement may significantly impact bond strength and, the lower the contact angle, the higher the shear bond strength [5]. Nonetheless, the surface wettability and the small contact angle between zirconia and cement after MV5 application was not enough to promote sufficient adhesion to survive sample preparation and pre-test failure was as high as that of control samples, without any primer application. Results also indicate that at least $0.1 \mathrm{wt} \%$ of MDP (MV6) is required in the formulation to avoid spontaneous failure.

When evaluating the effect of artificial aging on microtensile bond strength after primer application, results indicated that storage time had no significant effect. Therefore, this research fails to reject the second null hypothesis. In this study, beams with a cross-sectional area of approximately $1 \mathrm{~mm} 2$ were stored in water at room temperature for either $48 \mathrm{~h}$ or 180 days. Given the small cross-section of the adhesive interface, some hydrolytic degradation of the bonding was expected after 180 days water storage. However, the mode of failure presented by the experimental groups (Figure 1) do not indicate the degradation of the zirconia-cement adhesive interface, but the degradation of the bonding in other sites of the adhesive interface. In a previous study, only samples treated with MDP/VBATDT commercial primer and bonded with a methacrylated phosphoric ester-based cement showed stable bond strength after aging [19]. Nonetheless, in another study the same adhesive strategy resulted in significant decrease of bond strength after six months [28]. Many factors may be related to the stability of the bonding in the present study. The acidic functional monomer present in the MDP formulation has been considered relatively stable to hydrolysis due to its long carbonyl chain $[14,20]$. The homogenous coverage of the surface with the MDP/VBATDT solution and the chemical affinity between both molecules and the zirconia oxide layer may have reduced water penetration at the 
zirconia-primer interface. Additionally, an effective bonding between the methacryloyl groups in the MDP molecules, the vinyl groups in the VBATDT molecules and the methacrylate-based resin cement may have occurred, minimizing water penetration at the primer/resin cement interface.

The bond strength values for the primer-treated specimens that withstood sample preparation ranged from 9.1 to $15.1 \mathrm{MPa}$. As mentioned above, cutting is a critical step for the adhesive interface of zirconia-bonded specimens, due to the resistance offered by the fully sintered Y-TZP substrate and the possible vibration of the blade during the extensive cutting procedures. Therefore, it is possible to assume that the same chemical treatment would offer better bond strength values in a regular scenario. In dentistry, for example, it has been stated that the minimum bond strength values for acceptable clinical bonding should stay within 10 and $13 \mathrm{MPa}[24,37]$. Hence, the findings of the present study indicate that it is possible to generate Y-TZP-based restorations with clinically-acceptable bond strength without the need for alumina blasting the surface, as long as the primer treatment combines MDP and VBATDT molecules in a concentration of at least $0.5 \mathrm{wt} \% \mathrm{MDP}$ and $0.1 \mathrm{wt} \%$ VBATDT. Therefore, to expand the results of the current study, the interaction between the chemical treatments and cements with dissimilar composition should be further investigated.

\section{Conclusions}

The findings of the present study demonstrate that both monomers, MDP and VBATDT, are critical for bonding to non-air particle abraded Y-TZP. The balanced highest concentration of both monomers $(0.5 \mathrm{wt} \%)$ resulted in the highest initial bond strength results and aging did not affect the overall bond strength values.

Acknowledgments: The authors acknowledge Kuraray America Inc. for the preparation of the experimental primers and other materials' donation. We also would like to express our gratitude to Paulo F. Cesar for proofreading the article. Costs with chemical and mechanical analyses were supported by Grace M. De Souza's University of Toronto start-up fund.

Author Contributions: Grace M. De Souza conceived and designed the experiments; Anuj Aggarwal performed the experiments; Grace M. De Souza and Anuj Aggarwal analyzed the data and wrote the manuscript.

Conflicts of Interest: The authors declare no conflict of interest.

\section{References}

1. Jiang, S.P.; Love, J.G.; Zhang, J.P.; Hoang, M.; Ramprakash, Y.; Hughes, A.E.; Badwal, S.P.S. The electrochemical performance of LSM/zirconia-yttria interface as a function of a-site non-stoichiometry and cathodic current treatment. Solid State Ionics 1999, 121, 1-10. [CrossRef]

2. Christel, P.; Meunier, A.; Heller, M.; Torre, J.P.; Peille, C.N. Mechanical properties and short-term in-vivo evaluation of yttrium-oxide-partially-stabilized zirconia. J. Biomed. Mater. Res. 1989, 23, 45-61. [CrossRef] [PubMed]

3. Piconi, C.; Maccauro, G. Zirconia as a ceramic biomaterial. Biomaterials 1999, 20, 1-25. [CrossRef]

4. Devigus, A.; Lombardi, G. Shading vita In-ceram YZ substructures: Influence on value and chroma, part II. Int. J. Comput. Dent. 2004, 7, 379-388. [PubMed]

5. Kim, M.J.; Kim, Y.K.; Kim, K.H.; Kwon, T.Y. Shear bond strengths of various luting cements to zirconia ceramic: Surface chemical aspects. J. Dent. 2011, 39, 795-803. [CrossRef] [PubMed]

6. Behr, M.; Proff, P.; Kolbeck, C.; Langrieger, S.; Kunze, J.; Handel, G.; Rosentritt, M. The bond strength of the resin-to-zirconia interface using different bonding concepts. J. Mech. Behav. Biomed. Mater. 2011, 4, 2-8. [CrossRef] [PubMed]

7. Borges, G.A.; Sophr, A.M.; de Goes, M.F.; Sobrinho, L.C.; Chan, D.C. Effect of etching and airborne particle abrasion on the microstructure of different dental ceramics. J. Prosthet. Dent. 2003, 89, 479-488. [CrossRef]

8. Blatz, M.B.; Oppes, S.; Chiche, G.; Holst, S.; Sadan, A. Influence of cementation technique on fracture strength and leakage of alumina all-ceramic crowns after cyclic loading. Quintessence Int. 2008, 39, 23-32. [PubMed]

9. Pereira, L.D.; Campos, F.; Dal Piva, A.M.D.; Gondim, L.D.; Souza, R.; Ozcan, M. Can application of universal primers alone be a substitute for airborne-particle abrasion to improve adhesion of resin cement to zirconia? J. Adhes. Dent. 2015, 17, 169-174. 
10. Zhang, Y.; Lawn, B.R.; Rekow, E.D.; Thompson, V.P. Effect of sandblasting on the long-term performance of dental ceramics. J. Biomed. Mater. Res. B 2004, 71, 381-386. [CrossRef] [PubMed]

11. Kosmac, T.; Oblak, C.; Jevnikar, P.; Funduk, N.; Marion, L. Strength and reliability of surface treated Y-TZP dental ceramics. J. Biomed. Mater. Res. 2000, 53, 304-313. [CrossRef]

12. Scherrer, S.S.; Cattani-Lorente, M.; Vittecoq, E.; de Mestral, F.; Griggs, J.A.; Wiskott, H.W. Fatigue behavior in water of Y-TZP zirconia ceramics after abrasion with 30 mum silica-coated alumina particles. Dent. Mater. 2011, 27, e28-e42. [CrossRef] [PubMed]

13. Casucci, A.; Goracci, C.; Chieffi, N.; Monticelli, F.; Giovannetti, A.; Juloski, J.; Ferrari, M. Microtensile bond strength evaluation of self-adhesive resin cement to zirconia ceramic after different pre-treatments. Am. J. Dent. 2012, 25, 269-275. [PubMed]

14. Gomes, A.L.; Castillo-Oyague, R.; Lynch, C.D.; Montero, J.; Albaladejo, A. Influence of sandblasting granulometry and resin cement composition on microtensile bond strength to zirconia ceramic for dental prosthetic frameworks. J. Dent. 2013, 41, 31-41. [CrossRef] [PubMed]

15. Matinlinna, J.P.; Lassila, L.V.; Vallittu, P.K. Pilot evaluation of resin composite cement adhesion to zirconia using a novel silane system. Acta Odontol. Scand. 2007, 65, 44-51. [CrossRef] [PubMed]

16. Lohbauer, U.; Zipperle, M.; Rischka, K.; Petschelt, A.; Muller, F.A. Hydroxylation of dental zirconia surfaces: Characterization and bonding potential. J. Biomed. Mater. Res. B 2008, 87, 461-467. [CrossRef] [PubMed]

17. Yun, J.Y.; Ha, S.R.; Lee, J.B.; Kim, S.H. Effect of sandblasting and various metal primers on the shear bond strength of resin cement to Y-TZP ceramic. Dent. Mater. 2010, 26, 650-658. [CrossRef] [PubMed]

18. Yagawa, S.; Komine, F.; Fushiki, R.; Kubochi, K.; Kimura, F.; Matsumura, H. Effect of priming agents on shear bond strengths of resin-based luting agents to a translucent zirconia material. J. Prosthodont. Res. 2017, 17, 1883-1958. [CrossRef] [PubMed]

19. De Souza, G.M.; Silva, N.R.; Paulillo, L.A.; De Goes, M.F.; Rekow, E.D.; Thompson, V.P. Bond strength to high-crystalline content zirconia after different surface treatments. J. Biomed. Mater. Res. B 2010, 93, 318-323. [CrossRef] [PubMed]

20. De Oyague, R.C.; Monticelli, F.; Toledano, M.; Osorio, E.; Ferrari, M.; Osorio, R. Influence of surface treatments and resin cement selection on bonding to densely-sintered zirconium-oxide ceramic. Dent. Mater. 2009, 25, 172-179. [CrossRef] [PubMed]

21. Sciasci, P.; Abi-Rached, F.O.; Adabo, G.L.; Baldissara, P.; Fonseca, R.G. Effect of surface treatments on the shear bond strength of luting cements to Y-TZP ceramic. J. Prosthet. Dent. 2015, 113, 212-219. [CrossRef] [PubMed]

22. Kern, M.; Wegner, S.M. Bonding to zirconia ceramic: Adhesion methods and their durability. Dent. Mater. 1998, 14, 64-71. [CrossRef]

23. Dias de Souza, G.M.; Thompson, V.P.; Braga, R.R. Effect of metal primers on microtensile bond strength between zirconia and resin cements. J. Prosthet. Dent. 2011, 105, 296-303. [CrossRef]

24. De Souza, G.; Hennig, D.; Aggarwal, A.; Tam, L.E. The use of MDP-based materials for bonding to zirconia. J. Prosthet. Dent. 2014, 112, 895-902. [CrossRef] [PubMed]

25. Kim, J.H.; Chae, S.; Lee, Y.; Han, G.J.; Cho, B.H. Comparison of shear test methods for evaluating the bond strength of resin cement to zirconia ceramic. Acta Odontol. Scand. 2014, 72, 745-752. [CrossRef] [PubMed]

26. Akazawa, N.; Koizumi, H.; Nogawa, H.; Nakayama, D.; Kodaira, A.; Matsumura, H. Effect of mechanochemical surface preparation on bonding to zirconia of a trin-butylborane initiated resin. Dent. Mater. J. 2017, 36, 19-26. [CrossRef] [PubMed]

27. Koizumi, H.; Nakayama, D.; Komine, F.; Blatz, M.B.; Matsumura, H. Bonding of resin-based luting cements to zirconia with and without the use of ceramic priming agents. J. Adhes. Dent. 2012, 14, 385-392. [PubMed]

28. Da Silva, E.M.; Miragaya, L.; Sabrosa, C.E.; Maia, L.C. Stability of the bond between two resin cements and an yttria-stabilized zirconia ceramic after six months of aging in water. J. Prosthet. Dent. 2014, 112, 568-575. [CrossRef] [PubMed]

29. Shin, Y.J.; Shin, Y.; Yi, Y.A.; Kim, J.; Lee, I.B.; Cho, B.H.; Son, H.H.; Seo, D.G. Evaluation of the shear bond strength of resin cement to Y-TZP ceramic after different surface treatments. Scanning 2014, 36, 479-486. [CrossRef] [PubMed]

30. Yi, Y.A.; Ahn, J.S.; Park, Y.J.; Jun, S.H.; Lee, I.B.; Cho, B.H.; Son, H.H.; Seo, D.G. The effect of sandblasting and different primers on shear bond strength between yttria-tetragonal zirconia polycrystal ceramic and a self-adhesive resin cement. Oper. Dent. 2015, 40, 63-71. [CrossRef] [PubMed] 
31. Sanohkan, S.; Kukiattrakoon, B.; Larpboonphol, N.; Sae-Yib, T.; Jampa, T.; Manoppan, S. The effect of various primers on shear bond strength of zirconia ceramic and resin composite. J. Conserv. Dent. 2013, 16, 499-502. [PubMed]

32. Maeda, F.A.; Bello-Silva, M.S.; de Paula Eduardo, C.; Miranda Junior, W.G.; Cesar, P.F. Association of different primers and resin cements for adhesive bonding to zirconia ceramics. J. Adhes. Dent. 2014, 16, 261-265. [PubMed]

33. Stefani, A.; Brito, R.B., Jr.; Kina, S.; Andrade, O.S.; Ambrosano, G.M.; Carvalho, A.A.; Giannini, M. Bond Strength of Resin Cements to Zirconia Ceramic Using Adhesive Primers. J. Prosthodont. 2016, 25, 380-385. [CrossRef] [PubMed]

34. Silikas, N.; Wincott, P.L.; Vaughan, D.; Watts, D.C.; Eliades, G. Surface characterization of precious alloys treated with thione metal primers. Dent. Mater. 2007, 23, 665-673. [CrossRef] [PubMed]

35. Pashley, D.H.; Sano, H.; Ciucchi, B.; Yoshiyama, M.; Carvalho, R.M. Adhesion testing of dentin bonding agents: a review. Dent. Mater. 1995, 11, 117-125. [CrossRef]

36. Hummel, M.; Kern, M. Durability of the resin bond strength to the alumina ceramic Procera. Dent. Mater. 2004, 20, 498-508. [CrossRef] [PubMed]

37. Luthy, H.; Loeffel, O.; Hammerle, C.H. Effect of thermocycling on bond strength of luting cements to zirconia ceramic. Dent. Mater. 2006, 22, 195-200. [CrossRef] [PubMed]

(C) 2018 by the authors. Licensee MDPI, Basel, Switzerland. This article is an open access article distributed under the terms and conditions of the Creative Commons Attribution (CC BY) license (http:/ / creativecommons.org/licenses/by/4.0/). 